\title{
Evaluation In The Management of Cholidochlithiasis (Common Bile duct stones)
}

\author{
S.Gobishankar
}

Department of Surgery, Faculty of Medicine, Jaffna

\begin{abstract}
Common bile duct (CBD) stones affects around $5-15 \%$ of patient with gallbladder stones. Mainly it comes from gall bladder, but occasionally it can develop in the CBD itself. Patients will develop serious complications like acute pancreatitis, cholangitis, obstructive jaundice and secondary biliary cirrhosis. It is essential to exclude or confirm the CBD stones in patient with gall stones disease. Serum bilirubin and alkaline phosphatase levels and trans abdominal ultrasound scans were the basic investigation tools. With the technological development Magnetic resonance imaging MRI and laparoscopic ultrasound scan play important roles in the investigation of CBD stones. At the same times ERCP develops as a main diagnostic and therapeutic tool in the management of the CBD stones. After the introduction of the laparoscopy in the field of surgery it starts to contribute much in the management of biliary stones as well. Laparoscopic approach changes the two stage procedure of the gall stones disease as cholecystectomy and pre or post cholecystectomy ERCP in to single stage procedure. Aim of this article is to discuss the changes happen over the past few decades in the management of CBD stones and how and why it occurred.
\end{abstract}

\section{Introduction}

Gall stone disease is one of the common benign problem to the patients all over the world and it affects around 15 to $20 \%$ of the population worldwide.(1) Around 5-15\% of the people who have the gallstones will harbor the stones in the common bile duct (CBD). $(2,3)$ Cholidochlithiasis (CBD stones) is mainly due to stone migration from the gall bladder and denova stone formation in the CBD due to bile stasis, diverticulum or large bile duct.(4) Serious complications due to CBD stones includes obstructive jaundice, acute suppurative cholangitis, acute pancreatitis and secondary biliary cirrhosis.(5) In the pre-laparoscopic era treatment of CBD was straightforward which was open surgery. The change in the diagnostic and therapeutic intervention in the management of the CBD stones stated after invention of Endoscopic retrograde cholangiopancreatography (ERCP), Laparoscopy and Magnetic resonance imaging was marked. Major breakthrough in the management of CBD stones came in 1974 after the invention of the Endoscopic retrograde cholangiography. $(6,7)$ ERCP involves one of the two staged procedures which includes pre or post cholecystectomy endoscopic sphincterotomy with stone retrieval and cholecystectomy. Last two decades laparoscopic common bile duct exploration and stone removal has slowly replaced the Endoscopy method.(8)

\section{Investigation}

It is important to assess the CBD in each and every patients who are awaiting cholecystectomy. Patients with normal CBD diameter and liver function test will have up to $5 \%$ risk of having CBD stones. At the same time increased bilirubin levels and / or alkaline phosphatase levels increase the CBD stone risks to 33 to $66 \%$. A CBD diameter $12 \mathrm{~mm}$ or more with combination of other factors makes the risks of having the CBD stones to 90 to $100 \%$.(9)

Serum bilirubin level is one of the basic investigation with good predictive value in detecting CBD stones in a patient with acute cholecystitis or biliary colic. Further studies reveal, patients with elevated serum bilirubin level should be investigated for CBD stones rather than doing series of bilirubin level in an interval.(10)

Trans abdominal Ultrasound scan (US) is freely available test to detect the CBD dilatation and stones within it. But it has low sensitivity (Around 35\%) to detect the $\mathrm{CBD}$ stones therefore it is not reliable in selecting the patients for CBD intervention. (11)Dilated CBD has a good predictive value for having stones. Therefore these patients should undergo further evaluation by Magnetic Resonance Cholangiography(MRC) or Intra Operative Cholangiography (IOC).(12)

Vol.30, No.1, July 2018 
CT Cholangiography is a useful investigation to detect the CBD stones with sensitivity of $90 \%$ and specificity of $85 \%$. MRC is a most accurate noninvasive investigation to detect the $\mathrm{CBD}$ stones with sensitivity of $90 \%$ and specificity of $95 \%$.(13)

MRC is a good investigation method to detect the CBD stones even in a normal Ultrasound Scan and liver enzymes. But it misses the small stone $<$ $4 \mathrm{~mm}$ in size. Therefore unless any suspicious in the history or investigation no need to do the MRC.(14)

Intraoperative investigations include IOC and Laparoscopic US (LUS). IOC is a well-known investigation to detect CBD stones but there is a debate going on, weather it is necessary in all the patients undergoing laparoscopic cholecystectomy or it could be used selectively.

Recent studies show that asymptomatic CBD stones rarely stay in the $\mathrm{CBD}$ after cholecystecomy. (15) Another study done by Spinn MP, Wolf DS et al. showed nearly $50 \%$ of patients with positive IOC for stones have normal ERCP.(16)Therefor IOC will be avoided safely in these patients and it is more useful in patients with the risk factors for CBD stones mentioned initially.

LUS is recently introduced investigation in detecting the CBD stones. Its sensitivity is about $93 \%$ and specificity nearly $100 \%$.I t is less invasive than IOC. Therefore it is recommended to use the LUS as a routine basis and use IOC selectively when LUS is not successful or unsatisfactory.(17, 18)

\section{Management}

There is no ideal treatment of CBD stones. Management options for CBD stone includes surgical and endoscopic technique. Main surgical techniques are open and laparoscopic method and in each technique includes trans-cystic and choledocotomy approach. In endoscopic technique ERCP is used. Percutaneous tranhepatic cholangiogram and drainage is done by interventional radiologist, usually reserved for the patients who are not suitable for open and endoscopic methods.(18) Patients with cholangitis, CBD stones mainly managed by ERCP. $(19,20,21)$ But patients without cholangitis both operative and endoscopic methods could be applicable.
Selection of the management option for CBD stones mainly depend on the patient factors, disease factors and external factors. Patient factors includes co-morbidity and the fitness for general anaesthesia or sedation. Disease factors includes stone size, number of stone, CBD diameter and weather patient is having CBD infection or not. External factors mainly involves the availability of the expertise and instruments to perform the particular procedure.(22)

Before the advent of ERCP open surgical technique was undertaken and here during the surgery IOC was done through tanscystic approach to detect the CBD stone and choledocotomy was made to remove the stone. This opening was closed with $\mathrm{T}$ tubes. Its morbidity was $10-15 \%$, mortality of $<1 \%$ and retained stone rate was less than $6 \%$.(23) This traditional surgical method gradually changed over the last 4 decades with the technological advances that happened in the world and in the medical field.

\section{Endoscopic Retrograde Cholangiopancreatograph}

After the introduction of ERCP in 1974 it had a major role in the CBD stone extraction, which was safely and effectively used in pre or post cholecystectomy in patient with cholilithiasis and cholidocholithiasis.(24)In ERCP Sphincterotomy and papillary large balloon dilatation were the primary techniques used to dilate the papillae. Most frequently sphicterotomy with balloon trawling was used to remove the CBD stones.(29) Large balloon dilatation is more useful to remove the large stones from the CBD.(25)ERCP stone clearance rate is slightly higher than the laparoscopic CBD stone removal. CBD stone clearance rate in ERCP was $97 \%$ and $87 \%$ in laparoscopic surgery patients. (26) Some studies suggest that Laparoscopic cholecystectomy combined with intraoperative ERCP will be the safe and an effective technique in patients with cholecysto-cholidocolithiasis. In addition this technique shows reduction in post ERCP pancreatitis.(28) Endoscopic papillary large balloon dilation, mechanical lithotripter and cholangioscopic assisted methods will increase the stone extraction rate in ERCP.(29)

Endoscopic papillary large balloon dilation is a new technique where limited papillary sphincterotomy followed by dilatation of the papillae with a balloon. 
It will help to retrieve large CBD stones and a safest method in patients with periampullary diverticula. This technique will reduce most of the complication that occur during the ERCP.(30) In some patient during ERCPstone removal will not be complete due to large stone, multiple stones and elderly patients who are not suitable for sedation or anaesthesia to complete the procedure. In these situation temporary or permanent CBD stent placement is an acceptable solution.(31) Unfortunately ERCP has some serious complications included acute pancreatitis, haemorrhage, cholangitis, duodenal perforation and mortality.(27)

Failure ofERCP CBD stone removal is commonly due to impacted large CBD stone, duodenal diverticulum, stricture at the CBD or upper gastrointestinal anatomical variation due to past surgery.(32) Recent study reveals, ERCP with sphincterotomy remains the commonly done procedure for CBD stones and it is associated with high recurrent CBD stone formation compared to the other newer methods.(33) In addition to this, sphincterotomy may create stenosis of the papillae, recurrent cholangitis and common bile duct malignancy.(34)

After the advent of the laparoscopic CBD exploration, the role of ERCP and sphincterotomy must be think at least in younger population. However in Sri Lanka ERCP is a safe and feasible method for diagnosis and treatment for residual common bile duct stones after laparoscopic cholecystectomy.(35)

\section{Laparoscopic Common Bile Duct Exploration (LCBDE)}

LECBD effectively detects and clears the CBD stone like ERCP. However compared to ERCP it has shorter overall operation theatre time and hospital stay.(36,37)LCBDE mainly involves with transcystic approach and choledocotomy approach. In transcystic approach CBD will be approached through the cystic duct. IOC will be used to detect the unsuspected CBD stones and at the same time it can be used to confirm the stone clearance from the CBD and by this reduce the rate of retained CBD stones. $(38,39)$

Topal B. et al. (2007) study reveals average hospital stay after transcystic approach was 2 days and choledocotomy 6 days. Average diameter of the CBD in patients with choledocotomy is $11.5 \mathrm{~mm}$. And in successful transcystic approach average stone size was $5 \mathrm{~mm}$. Finally average operation time for trancystic approach was 75 minutes and 107 minutes for choledocotomy approach. Therefore trans-cystic approach is suitable in majority of patients with small stones and cholidochotomy should be reserved for large stones which cannot be removed through the cystic duct.(40) Another study done by Darrien D H. reveals that choledocotomy done CBD stones only when its diameter $>8 \mathrm{~mm}$. (41) Basket retrieval, balloon retrieval, saline flushing and flexible choledochoscope techniques were used to remove the stones and confirm the stone clearance from the CBD.(42) In laparoscopic trans-cystic CBD exploration, initially stone will confirmed by IOC through cystic duct or flexible choledochoscope. (Flexible choledocoscope usually available in $3 \mathrm{~mm}$ in size, which can be inserted in to the abdominal cavity through one of the $5 \mathrm{~mm}$ laparoscopic port. This will negotiate in to the CBD through cystic duct or choledocotomy opening.)

Laparoscopic transcystic approach shows similar stone clearance rate but shorter operative time, lesser blood loss and other complication compared to the choledocotomy approach.(43) But when using the flexible choledochoscope stone clearance rate is slightly higher in addition to reduce the rate of retain stone without any added complications. (44)

Laparoscopic technique is safe even in a patient with previous upper abdominal surgery. But it may take some additional time to separate the adhesion to expose the CBD.(45) After the choledocotomy traditionally CBD will be closed with $\mathrm{T}$ tube. With the advance of laparoscopic surgical skills surgeons try to close the CBD primarily. And this primary CBD closure is a safe and effective method after CBD Exploration, but it needs a good laparosopic surgical skills with a long learning curve.(46)

LECBD usually combined with laparoscopic cholecystectomy when a patient present with cholecysto-choledocholithiasis as a single stage procedure. This operative technique is superior than two stage laparoscopic cholecystectomy with pre-post ERCP in terms of technical success and 
shorter hospital stay.(47) This is an effective and a safe procedure for CBD stones with less morbidity and mortality. This procedure will reduce the need for unnecessary ERCP in future.(48) As it is a single procedure with early return to home, LECBD reduces the hospital cost without any increase in the complication rate.(49)

There are some independent risk factors like maximum diameter of the CBD stone, oedematous CBD and multiple stones necessitate the laparoscopic CBD exploration in to open surgery. Studies reveal its conversion rate is nearly $4 \%$. Even though LECBD is a safe procedure, post operative bile leakage is slightly higher when compared with laparoscopic chlecystecmy with ERCP.(50)

Recent meta analysis showed that LCBDE with cholecystectomy is superior to ERCP and Laparoscopic cholecystectomy in terms of safety and efficacy and it must be considered as foremost treatment option for the cholelithiasis with cholidocholithiasis.(51) And using the choledochoscope during the LCBDE is an ideal procedure to diagnose and treat the CBD stones nowadays.(52) During emergency surgeries like cholecystitis stone clearance rate in the LCBDL ranges between $65-98 \%$. This variation probably due to availability of the local expertise and resources. $(53,54)$

At the moment there is no protocol or standard treatment for CBD stones all over the world. But it is now treated either by ERCP or laparoscopic method. If the $\mathrm{CDB}$ dilatation is not significant then ERCP is more suitable when there is no expertise available to do the LCBDE. On the other hand dilated CBD or Large CBD stone $>1 \mathrm{~cm}$ then LCBDE will be the good option. Small stones can be extracted through the cystic duct and remain one need choledocotomy. Option will be decided by the particular surgeons / units treating the patient.

\section{Conclusion}

The current medical practice ERCP for CBD stone retrieval is the commonly undertaken technique for CBD stones. It has some complication in addition to recurrent stone formation and rare possibility of malignancy. Therefore emerging trend is towards
LCBDE. But it need some advanced laparoscopic skills in the surgeons who is doing the surgery and long learning curve. Even though there are some complication seen during the procedure it is a safe and a promising surgical technique which is cost effective. In future most of the centers which are performing laparoscopic cholecystectomy will move onto do LCBDE.

\section{References}

1. Everhart J E, Khare M, Hill M et al. Prevalence and ethnic differences in gallbladder disease in the United States. Gastroenterology 1999; 117: 632-9.

2. Collins $C$, Maguire D, Ireland A et al. A prospective study of common bile duct calculi in patients undergoing laparoscopic cholecystectomy: natural history of choledocholithiasis revisited. Ann. Surg. 2004; 239:28-33.

3. Freitas ML, Bell RL, Duffy AJ. Choledocholithiasis: evolving standards for diagnosis and management. World J. Gastroenterol. 2006; 12: 3162-7.

4. Collins C, Maguire D, Ireland A, Fitzgerald E, O'Sullivan GC. A prospective study of common bile duct calculi in patients undergoing laparoscopic cholecystectomy: natural history of choledocholithiasis revisited. Ann Surg. 2004;239:28-33

5. Williams E, Beckingham I, El Sayed G et al. Updated guideline on the management of common bile duct stones (CBDS). Gut 2017; 66: 765-782.

6. Classen M, Demling L. Endoscopic sphincterotomy of the papilla of Vater and extraction of stones from the choledochal duct. Dtsch. Med. Wochenschr. 1974; 99: 496-7.

7. Kawai K, Akasaka Y, Murakami Ket al. Endoscopic sphincterotomy of the ampulla of Vater. Gastrointest. Endosc. 1974; 20: 148-51.

8. Shojaiefard A, Esmaeilzadeh M, Ghafouri A, Mehrabi A. Various techniques for the surgical treatment of common bile duct stones: a meta review. Gastroenterol Res Pract. 2009;2009:840208.

9. François Lacaine, MD; Marvin B. Corlette, MD; Henri Bismuth, MD.Preoperative Evaluation of the Risk of Common Bile Duct Stones. Arch Surg. 1980;115(9):1114-1116.

10. Gillaspie DB, Davis KA, Schuster KM. Total bilirubin trend as a predictor of common bile duct stones in acute cholecystitis and symptomatic cholelithiasis. Am J Surg. 2018 Jun 18. pii: S00029610(18)30437-9.

11. Stott MA1, Farrands PA, Guyer PB, Dewbury KC, Browning JJ, Sutton R. Ultrasound of the common bile duct in patients undergoing cholecystectomy. 
J Clin Ultrasound. 1991 Feb;19(2):73-6.

12. Majeed A W, Ross B, Johnson A G, Reed M W. Common duct diameter as an independent predictor of choledocholithiasis: is it useful? Clin Radiol. 1999;54:170-172. [PubMed]

13. Kondo $\mathrm{S}$, Isayama $\mathrm{H}$, Akahane $\mathrm{M}$, Toda $\mathrm{N}$, Sasahira N, Nakai Y, Yamamoto N, Hirano K, Komatsu Y, Tada M, et al. Detection of common bile duct stones: comparison between endoscopic ultrasonography, magnetic resonance cholangiography, and helicalcomputed-tomographic cholangiography. Eur J Radiol. 2005;54:271-275. [PubMed]

14. Jendresen M B, Thorboll J E, Adamsen S, Nielsen $\mathrm{H}$, Gronvall S, Hart-Hansen O. Preoperative routine magnetic resonance cholangiopancreatography before laparoscopic cholecystectomy: a prospective study. Eur J Surg. 2002;168(12):690-4.

15. Horwood J, Akbar F, Davis K, Morgan R. Prospective evaluation of a selective approach to cholangiography for suspected common bile duct stones. Ann R Coll Surg Engl. 2010 Apr;92(3):20610.

16. Spinn M P, Wolf D S, Verma D, Lukens F J. Prediction of which patients with an abnormal intraoperative cholangiogram will have a confirmed stone at ERC.Dig Dis Sci. 2010 May;55(5):1479-84.

17. Machi J, Oishi AJ, Tajiri T, Murayama K M, Furumoto N L, Oishi RH. Routine laparoscopic ultrasound can significantly reduce the need for selective intraoperative cholangiography during cholecystectomy. Surg Endosc. 2007;21:270-274. [PubMed]

18. Perry KA, Myers JA, Deziel DJ. Laparoscopic ultrasound as the primary method for bile duct imaging during cholecystectomy. Surg Endosc. 2008;22:208-213. [PubMed]

19. Dasari B V, Tan C J, Gurusamy K S, Martin D J, Kirk G, McKie L, Diamond T, Taylor MA. Surgical versus endoscopic treatment of bile duct stones. Cochrane Database Syst Rev. 2013;12:CD003327. [PubMed]

20. Dasari B V, et al. Surgical versus endoscopic treatment of bile duct stones. Cochrane Database Syst Rev. 2013;(9): p. CD003327. [PubMed]

21. Abu Dayyeh B K. Endoscopic sphincterotomy: indications, techniques, and adverse events. Tech gas int end. 2012;14(3):141-147.

22. Sebastiano L, Martino M. Management of Common Bile Duct Stones: a Ten-Year Experience at a Tertiary Care Center. JSLS. 2008 Jan-Mar; 12(1): 62-65.

23. Ko C W, Lee S P. Epidemiology and natural history of common bile duct stones and prediction of disease. Gastrointest Endosc. 2002;56(Suppl 6):S165-S169. [PubMed]
24. Cisek P L, Greaney G C. The role of endoscopic retrograde cholangiopancreatography with laparoscopic cholecystectomy in the management of choledocholithiasis. Am Surg. 1994;60(10):772776.

25. Park C H. The Management of Common Bile Duct Stone. Korean J Gastroenterol. 2018 May 25;71(5):260-263.

26. Xiaohong Wang, Chenguang Dai, Zhonghua Jiang, Lili Zhao, Min Wang, Limei Ma, Xueming Tan, Li Liu, Xiang Wang, and Zhining Fan. Endoscopic retrograde cholangiopancreatography versus laparoscopic exploration for common bile duct stones in post-cholecystectomy patients: a retrospective study. Oncotarget. 2017 Oct 10; 8(47): 82114-82122.

27. Wang $P$, Li ZS, Liu F, Ren X, Lu NH, Fan ZN, Huang Q, Zhang X, He LP, Sun WS, Zhao Q, Shi $\mathrm{RH}$, Tian ZB, et al. Risk factors for ERCP-related complications: a prospective multicenter study. Am J Gastroenterol. 2009;104:31-40.

28. Ghazal A H, Sorour M A, El-Riwini M, El-Bahrawy $\mathrm{H}$. Single-step treatment of gall bladder and bile duct stones: a combined endoscopic-laparoscopic technique. Int J Surg. 2009 Aug;7(4):338-46.

29. Doshi B, Yasuda I, Ryozawa S, Lee GH. Current endoscopic strategies for managing large bile duct stones. Dig Endosc. 2018 Apr;30 Suppl 1:59-66.

30. Zulli C, Grande G, Tontini GE, Labianca O, Geraci G, Sciumè C, Antypas P, Fiocca F, Manes G, Devani M, Manta R, Maurano A. Endoscopic papillary large balloon dilation in patients with large biliary stones and periampullary diverticula: Results of a multicentric series. Dig Liver Dis. 2018 Apr 6. pii: S1590-8658(18)30675-3.

31. Mohammed N, Pinder M, Harris Ket al. Endoscopic biliary stenting in irretrievable common bile duct stones: stent exchange or expectant managementtertiary-centre experience and systematic review. Frontline Gastroenterol. 2016; 7: 176-186.

32. Garg PK, Tandon R K, Ahuja V, Makharia G K, Batra Y. Predictors of unsuccessful mechanical lithotripsy and endoscopic clearance of large bile duct stones. Gastrointest Endosc. 2004;59:601-605.

33. Pan L, Chen M, Ji L, Zheng L, Yan P, Fang J, Zhang $B$, Cai X. The Safety and Efficacy of Laparoscopic Common Bile Duct Exploration Combined with Cholecystectomy for the Management of Cholecysto-choledocholithiasis: An Up-to-date Meta-analysis. Ann Surg. 2018 Aug;268(2):247253.

34. Schreurs WH, Juttmann JR, Stuifbergen WN, Oostvogel HJ, van Vroonhoven TJ. Management of common bile duct stones: selective endoscopic retrograde cholangiography and endoscopic

Vol.30, No.1, July 2018 
sphincterotomy: short- and long-term results. Surg Endosc. 2002;16:1068-1072. [PubMed]

35. Liyanage A S, Gamage B D, de Silva W M. Management and outcome of residual bile duct stones following cholecystectomy at a tertiary referral centre in Sri Lanka. Ceylon Med J. 2007 Dec;52(4):122-4.)

36. M. Rhodes, L. Sussman, L. Cohen, M.P.Lewis. Randomised trial of laparoscopic exploration of common bile duct versus postoperative endoscopic retrograde cholangiography for common bile duct stones. The Lancet. Volume 351, Issue 9097, 17 January 1998, Pages 159-161.

37. Stanley J. Rogers, John P. Cello, Jan K. Horn, Allan E. Siperstein, William P. Schecter, Andre R. Campbell, Robert C. Mackersie, Alex Rodas, CCRC; Huub T. C. Kreuwel, Hobart W. Harris. Prospective Randomized Trial of LC+LCBDE vs ERCP/S+LC for Common Bile Duct Stone Disease. Arch Surg. 2010;145(1):28-33.

38. Edye M, Dalvi A, Canin-Endres J, Baskin-Bey $E$, Salky B. Intraoperative cholangiography is still indicated after preoperative endoscopic cholangiography for gallstone disease. Surg Endosc. 2002;16(5):799-802. doi: 10.1007/ s00464-001-8244-1.

39. Sirinek K R, Schwesinger W H. Has intraoperative cholangiography during laparoscopic cholecystectomy become obsolete in the era of preoperative endoscopic retrograde and magnetic resonance cholangiopancreatography? J Am Coll Surg. 2015;220(4):522-528. doi: 10.1016/j. jamcollsurg.2014.12.043.

40. Topal B, Aerts R, Penninckx F. Laparoscopic common bile duct stone clearance with flexible choledochoscopy.Surg Endosc. 2007 Dec;21(12):2317-21.

41. Darrien J H, Connor K, Janeczko A, Casey J J, Paterson-Brown S. The Surgical Management of Concomitant Gallbladder and Common Bile Duct Stones. HPB Surg. 2015; 2015: 165068. Published online 2015 Sep 1. doi: 10.1155/2015/165068

42. Phillips E H, Rosenthal R J, Carroll B J, Fallas M J. Laparoscopic trans-cystic-duct common-bile-duct exploration. Surg Endosc. 1994 Dec;8(12):138993.

43. Pang L, Zhang Y, Wang Y, Kong J. Transcystic versus traditional laparoscopic common bile duct exploration: its advantages and a meta-analysis. Surg Endosc. 2018 Jun 25. doi: 10.1007/s00464018-6286-x.

44. Harikrishnan K M,Selvaraj S, Rajgopal G. Our experience with diagnostic and therapeutic choledochoscopy. Med J Armed Forces India. 1997 Apr; 53(2): 116-118. Published online 2017 Jun 26. doi: 10.1016/S0377-1237(17)30679-2
45. Zhu J, Sun G, Hong L, Li X, Li Y, Xiao W. Surg Laparoscopic common bile duct exploration in patients with previous upper abdominal surgery. Endosc. 2018 Jun 4. doi: 10.1007/s00464-0186248-3

46. Zhu H, Wu L, Yuan R, Wang Y, Liao W, Lei J, Shao J. Learning curve for performing choledochotomy bile duct exploration with primary closure after laparoscopic cholecystectomy. Surg Endosc. 2018 Mar 30. doi: 10.1007/s00464-018-6175-3.

47. Singh A N, Kilambi R. Single-stage laparoscopic common bile duct exploration and cholecystectomy versus two-stage endoscopic stone extraction followed by laparoscopic cholecystectomy for patients with gallbladder stones with common bile duct stones: systematic review and meta-analysis of randomized trials with trial sequential analysis. Surg Endosc. 2018 Mar 30. doi: 10.1007/s00464018-6170-8

48. Muhammed A M, Hesham H, Mohammed I M. Laparoscopic common bile duct exploration: the past, the present, and the future.The American Journal of Surgery. Volume 179, Issue 4, April 2000, Pages 309-315.

49. Gilsdorf D, Henrichsen J, Liljestrand K, Staheli A, Olsen G, Narayanan P, Ott M, Morris DS, Price R.Laparoscopic Common Bile Duct Exploration for Choledocholithiasis: Analysis of Practice Patterns of Intermountain HealthCare. J Am Coll Surg. 2018 Jun;226(6):1160-1165.

50. Ricci C, Pagano N, Taffurelli G Pacilio CA, Migliori M, Bazzoli F, Casadei R, Minni F.Comparison of Efficacy and Safety of 4 Combinations of Laparoscopic and Intraoperative Techniques for Management of Gallstone Disease With Biliary Duct Calculi: A Systematic Review and Network Metaanalysis. JAMA Surg. 2018 May 30:e181167. doi: 10.1001/jamasurg.2018.1167.

51. Pan L, Chen M, Ji L, Zheng L, Yan P, Fang J, Zhang B, Cai X. The Safety and Efficacy of Laparoscopic Common Bile Duct Exploration Combined with Cholecystectomy for the Management of Cholecysto-choledocholithiasis: An Up-to-date Meta-analysis. Ann Surg. 2018Aug;268(2):247-253

52. Disci E, Atamanalp SS, Ozogul B, Yildirgan MI. The Role of Choledochoscopy in Hepatopancreatobiliary Diseases. Eurasian J Med. 2016 Feb;48(1):29-32.

53. PohB, Cashin P, BowersK,Ackermann T, Tay YK, Dhir A, Croagh D.. Management of choledocholithiasis in an emergency cohort undergoing laparoscopic cholecystectomy: a single-centre experience. HPB (Oxford) 2014;16(7):629-634.

54. Lee H M, Min S K, Lee HK. Long-term results of laparoscopic common bile duct exploration by choledochotomy for choledocholithiasis: 15-year experience from a single center. Ann Surg Treat Res. 2014;86(1):1-6 